\title{
Examining the (Lack of) Effects Associated with Leadership Training Participation in Higher Education
}

\author{
Dr. David M. Rosch
}

\begin{abstract}
This study examined the differences between a multi-campus sample of university students who reported consistent participation in formal leadership development programs $(n=414)$ and a comparison sample $(n=153)$ with no prior experience across three diverse postsecondary institutions in the United States. Both samples were matched with regard to gender and racial identity, prior self-reported high school leadership training experience, and selfreported possession of formal leadership positions in co-curricular student organizations. Results suggest that students who report past consistent participation in postsecondary leadership training report levels of leadership capacity no different than those with no training. In addition, like their peers they also possess a cognitive model of leadership capacity that fails to differentiate leader self-efficacy, motivation to lead, and leadership skill.
\end{abstract}

\section{Introduction}

A clear need exists in contemporary society to produce adults with a higher capacity for leading organizations than currently exists (Komives \& Wagner, 2017). Today's employers of university graduates list leadership and problem-solving skills as consistently necessary capacities for students to develop, while also stating that these skills are most often lacking in job seekers (Banerji, 2007; National Association of Colleges and Employers, 2015). By several measures, confidence in the leadership capacity of our corporate, political, and community leaders has never been lower (Rosenthal, 2012). In part as a response to these challenges, universities have significantly increased the number and depth of their leadership-related programs (Dugan \& Komives, 2007; Owen, 2012). The International Leadership Association, for example, currently lists over 2,000 formal programmatic offerings in the form of leadership majors, minors, certification programs, and co-curricular initiatives (International Leadership Association, 2017). However, such increases have not necessarily resulted in consistent development in students across programs or institutions (Dugan, 2011; Dugan et al., 2011). While several past research efforts (e.g. Cress, Astin, Zimmerman-Oster, \& Burkhardt, 2001) suggest participation in formal co-curricular leadership is associated with increased scores of leadership capacity (i.e. where students possess the potential for practicing effective leadership), few (e.g. Rosch \& Caza, 2011) attempt to do more than correlate higher scores with participation (Dugan, 2011).

Despite the number of program offerings, a national survey of formal co-curricular leadership programs in the United States revealed that most of them were labeled as "new" or "building capacity" (Owen, 2012). In addition, several programs reported utilizing foundational curriculum that many leadership theorists would say are only peripherally related to the study and practice of effective leadership, such as personality assessments or Covey's Seven Habits of Highly Effective People (Covey, 2004). The overall study results led the coordinating author to 
conclude that leadership development programming in post-secondary education, "faces [an] awkward adolescent phase" (p. 20) where the structure and curriculum of initiatives should shift to match a growing body of research suggesting good practice. In response to these challenges, this study examined the differences between a multi-campus sample of students who reported consistent prior participation in formal post-secondary leadership development programs and a matched comparison sample who reported no such prior participation. We were interested not only in comparing scores on quantitative measures of leadership capacity, but in also examining the cognitive models of leadership capacity of students who report a significant degree of prior experience compared to their peers with no prior experience. More specifically, we investigated if students who participated in leadership programs were better able to distinguish, within their own understanding of their beliefs and behaviors, among the separate concepts of leadership skill, leader self-efficacy, and motivation to lead.

A Conceptual Impact Model of Leadership Education. A lack of clarity currently exists regarding both the conceptualizations of leadership capacity that are most commonly espoused in postsecondary education and the outcome models leadership educators utilize in assessing the impact of their efforts. Within this study, we used the "Ready, Willing, and Able" model of leadership education (Keating, Rosch, \& Burgoon, 2014) to inform our efforts. The model is generally related to an increasing focus on the study of leadership competencies (e.g. Dugan, 2011; Seemiller \& Miller, 2013), where researchers and educators state that the potential for effective practice of leadership must look beyond the possession of skill to include other factors, such as knowledge, motivation, and outlook.

Within the model, the authors advocate that after participating in initiatives designed to build leadership capacity, students should report being poised to act as a leader ("Ready") based on a strong sense of self-efficacy; feel a sense of motivation to engage in the behaviors of leading their peers ("Willing") when circumstances call for action; and report demonstrated successful actions based on possessing the skills necessary for leadership ("Able"). While not necessarily related to a leadership context, the organization of these three attributes into an integrated whole was first implemented in the United States military in preparing officers for World War I, and has been used as an optimal outcome in numerous developmental training programs since (Ammer, 2001). Moreover, the phrase "Ready, Willing, and Able" has grown into a cultural idiom meaning "well-prepared and eager to do something" (Ammer, 1997, p. 535). Each attribute, while related to the other two, is also distinct from them, and necessary to the effective enactment of leadership behaviors. For example, without motivation to lead, potentially high-capacity leaders might choose to remain in the background to avoid the difficult work of leading in complex environments. Without leader self-efficacy, a motivated and skilled leader may not possess the confidence to consistently step forward. Without skill, the actions of motivated and confident leaders may fail.

Leader self-efficacy ("ready"). Leader self-efficacy (LSE) refers to the degree to which potential leaders feel that their leader-oriented behaviors are likely to be successful (McCormick, 2001), and stems from Bandura's original concept of general self-efficacy (1977). It describes the extent to which potential leaders feel that they would be successful serving as a leader (Hoyt, 2005; Murphy \& Johnson, 2011). In essence, people who possess an elevated LSE are more likely to engage in the behaviors 
of leadership than those who possess a depressed LSE. Leader self-efficacy has been correlated with the success rate of leaders in a variety of professional settings (Avolio, Reichard, Hannah, Walumbwa, \& Chan, 2009; Hannah, Avolio, Luthans, \& Harms, 2008; Machida \& Schaubroeck, 2011) and has examined more recently in studies of university students in postsecondary institutions (Dugan, Garland, Jacoby, \& Gasiorski, 2008; Dugan \& Komives, 2007).

Motivation to lead ("willing"). Motivation to lead (MTL) is a psychological construct that refers to the degree of "psychological press" (Chan \& Drasgow, 2001) a person feels to act in ways generally defined as leadership behaviors. One's degree of motivation to lead can develop from any of three general areas of motivation: (1)

"Affective-identity" MTL is defined as the possession of a strong image of oneself as a leader, and therefore motivates one to lead based on this self-image; (2) A "noncalculative" MTL, where one's decision to lead is based on avoiding a self-centered calculation for how engaging in leadership behaviors will only benefit oneself individually; and (3) A "social-normative MTL" that grows from possessing a sense of responsibility to one's group and the members within it who look to that individual to lead (Chan \& Drasgow, 2001). Motivation to lead has been shown as a factor in leader success in professional organizations (Amit \& Bar-Lev, 2013; Derue \& Ashford, 2010) and more recently in collegiate settings as well (Rosch, Collier, \& Thompson, 2015).

Leadership skill ("able"). Within our conceptual model, leadership skill encompasses the two paradigms of leadership described within Transformational Leadership Theory (Bass, 1998), arguably the most popular current conceptualization of preferred leadership behavior (Dinh et al., 2014). Within the "transformational" paradigm, leader effectiveness stems from skill in developing positive and transformational relationships with followers, acting in ethical ways that serve the group and larger community, and enacting behaviors which result in achievement of group goals (Bass, 1998). "Transactional" leadership, by contrast, is focused more on the transactions involved between leaders and followers in achieving goals, such as motivating followers to action by rewarding productive behavior (Bass, 1998). While the transformational leadership paradigm is sometimes taught as more valuable in a leadership education context, both possess aspects required for successful leadership in contemporary organizations (Keating et al., 2014).

Measuring Leadership Development. Leadership educators possess a myriad of methods in which to assess the development of students as emerging leaders. Perhaps the most utilized technique in the field, based on the frequency of published research in education journals, is a two-stage repeated-measures analysis, where students complete a pre-test prior to program participation and a post-test at the program's conclusion, where changes in responses are analyzed. While relatively simple to implement, such a design has long been recognized for its potentially significant validity weaknesses such as response-shift bias (Howard, et al, 1979), especially within short-term leadership programs (Rosch \& Schwartz, 2009). A retrospective design, where students complete a retrospective pre-test "looking back" at the end of their participation while simultaneously completing a post-test within the same survey instrument was implemented to help alleviate these issues. However, retrospective designs created problems that 
weaken its validity in other ways, such as participant possession of flawed memories of prior states (Baddeley, 1979). While both have strengths and weaknesses, however, neither allow students the ability to apply their learning within their own contexts after and outside their educational experience, which would allow them to make a more accurate long-term assessment of their growth. However, while longitudinal studies can address these issues, this methodology is expensive, difficult to rigorously implement, and can suffer from significant participant mortality (Parker \& Pascarella, 2013).

Cross-sectional multi-university studies, where large groups of students are included in one-time measurement efforts, have the benefit of offering breadth in the number and diversity of students who can be included, especially if samples are collected through intelligent randomized sampling (Pearson, 2010). Within leadership impact studies in post-secondary education, a typical implementation is to compare the attributes of one subsample of students to another and draw potential conclusions about the correlation of these attributes to their different experiences (Dugan, 2011). However, many studies that implement cross-sectional analysis, including influential studies that examine differences in students who participate in leadership programs (e.g. Cress, Astin, Zimmerman-Oster, \& Burkhardt, 2001; Dugan et al., 2011) solely compare scale mean differences using multivariate regression techniques to draw conclusions regarding the outcomes of participation.

A more powerful technique that can and should be brought to bear in these types of analyses is confirmatory factor analysis (CFA), which is commonly used as a statistical tool for analyzing the observed structure of data and their relationship to their underlying latent constructs (Kline, 2011). Using CFA, researchers that are interested in complex cognitive phenomena possess the ability to analyze "goodness of fit" statistics that serve as cognitive representations of underlying latent cognitive and behavioral concepts (Blunch, 2013). Within this context, participants whose responses "fit" better (i.e. possess elevated goodness of fit statistical results) across their grouped responses to items on scales measuring disparate aspects of potential to engage in effective leadership behaviors can likely better distinguish between these separate concepts.

Students who are unable to distinguish among their leader self-efficacy, motivation to lead, and leadership skill are therefore unable to consciously leverage each of these capacities independently to behave as a "Ready, Willing, and Able" leader. For example, if a student's motivation to lead is indistinguishable from their leader self-efficacy, when that student does not feel confident in their chances of success in acting as a leader, they will also not be motivated. However, a student who can distinguish between the two is much more likely to attempt to lead, even if they do not feel confident, if they possess adequate motivation that doing so is worth it. Students who cannot distinguish between their leadership skill and leader self-efficacy may believe that if they are confident of their success, they also must be skilled. Students who can distinguish between the two are more likely to seek out necessary training when their skill is lacking. An impact study that compares the cognitive models of leadership capacity of students who participate in formal leadership development initiatives to those who do not participate, using the "Ready, Willing, and Able" model seems particularly well-suited for the use of CFA as an analytic technique (Rosch \& Caza, 2012) in a leadership education context. 
Effects of Leadership Training on Student Development. Given the problematic issues in comprehensively measuring the leadership development of students, research on the effects of participating in formal programs designed for leadership growth is, at best, mixed. Student leaders' scores in measures of leadership effectiveness are generally higher than for comparison groups who report lower amounts of participation (Cress et al., 2001; Dugan \& Komives, 2010; Kezar \& Moriarty, 2000). However, more nuanced research shows a different story. The most recent national study to examine the effects of formal program participation on student development, the Multi-Institutional Study of Leadership, suggested a small but statistically significant positive effect across programs (Dugan, et al., 2011). However, a large variation in outcomes emerged across campuses and programs within the study. A more recent longitudinal study within one campus showed a slight decrease in leadership capacity over the course of a semester when measured with multiple data points and utilizing advanced statistical techniques like multi-level modeling (Day \& Shin, 2011). The authors of the study suggested these disappointing results stemmed from when students would attempt to practice newlylearned behavior in challenging settings (Day \& Sin, 2011).

These troubling findings place pressure on the field of leadership education research to construct elegant and well-designed multi-campus studies aimed at determining the degree to which students grow in their leadership development after participating in formal educational programs. This study was intended to accomplish these goals, especially in how leadership development can be measured within cross-sectional, multi-campus datasets, and was focused on examining whether students who participate in formal co-curricular leadership programs possess a cognitive model of leadership capacity that is more strongly aligned with being a "Ready, Willing, and Able" leader.

Research Questions. Using a random sample of students collected from three postsecondary institutions intentionally chosen for their representativeness within the field of higher education in the United States, we sought to address the following questions:

1. Compared to a matched set of peers who report no experience in formal collegiate leadership experiences, do students who report a significant degree of prior experience also report higher degrees of leader self-efficacy, motivation to lead, and leadership skill?

2. To what extent do students who report a significant degree of prior experience also possess a more coherent cognitive model related to the capacity to lead within the "Ready, Willing, and Able" leadership model?

\section{Methods}

Population and Sample. The overall sample of students was drawn from three diverse post-secondary institutions in the United States: a highly selective public research extensive university in the Midwest; an open-access public university in the West; and an open-access community college in the Midwest. At each institution, a simple, random sample of 2,000 potential participants was drawn from within the population of matriculated undergraduate and graduate students. Of those who responded to the invitation, we only included participants who had completed at least $90 \%$ of the overall survey instrument within this study $(n=1226)$. 
The overall sample was then divided into two groups - students with a significant degree of prior experience in formal leadership programs and those with no formal experience. Within the survey that students received, one item was, "To what degree have you participated in formal leadership development programs, such as leadership programs, retreats, courses, etc.?" The response options were "Never," Once," "Sometimes," Often," and "Consistently." Due to the potential ambiguity of the meanings of each of these response options in the minds of participants, those who responded "Sometimes," Often," or "Consistently" were all collapsed into a single criterion group described as possessing a repeated degree of prior experience, while students who responded "Never" were situated as their comparison. Students who responded "Once" were removed from this analysis to ensure that the two groups were different enough for a valid comparison study. We then conducted propensity score analysis to create comparison datasets matched by gender and racial identity, class year, the degree to which students reported possessing a leadership position in a student organization, and the degree to which they reported participating in leadership training experiences while in high school.

The resulting datasets consisted of a total of 569 participants - 153 who reported no prior collegiate leadership training experience and 414 with repeated experience. Of these groups, $55 \%(\mathrm{n}=310)$ identified as a woman. Approximately $72 \%(\mathrm{n}=411)$ identified as White, $13 \%$ $(\mathrm{n}=76)$ as Asian-American, 3\% $(\mathrm{n}=16)$ as Latinx, 2\% $(\mathrm{n}=11)$ as African-American, 5\% $(\mathrm{n}=27)$ as multi-racial, and 5\% $(\mathrm{n}=28)$ chose not to identify their race. In regards to class year, $12 \%(\mathrm{n}=69)$ identified as a first-year student, $21 \%(\mathrm{n}=117)$ as a second-year, $27 \%(\mathrm{n}=151)$ as a third-year, $27 \%(\mathrm{n}=150)$ as a fourth-year, while $14 \%(\mathrm{n}=82)$ identified as a graduate student.

Instrumentation. In addition to survey items asking participants to report their gender, racial identity, and class year, we employed three popular scales designed to measure five different attributes related to creating "Ready, Willing, and Able" leaders. Each of the survey items included a Likert five-point scale ranging from "Strongly Disagree" to "Strongly Agree."

Leader self-efficacy ("ready"). We employed the Self-Efficacy for Leadership (SEL) scale, an 8-item instrument designed to measure the degree of confidence participants self-report in enacting leadership behaviors in a team context (Murphy \& Fiedler, 1992). The SEL has long been applied in professional contexts (e.g. Hoyt, 2005; Murphy, 2002). Prior studies that focus on its historic internal reliability report a high mean Cronbach's alpha of.86 (Murphy \& Ensher, 1999), while the overall alpha within this study was measured at .82 .

Motivation to lead ('willing"). To measure a participant's reported willingness to engage in leadership behaviors, we utilized the multi-faced Motivation to Lead (MTL) scale, a 27-item instrument which includes three foundations for leadership motivations equally divided across three sub-scales aligned with the three foundations of motivation to lead described earlier (Chan \& Drasgow, 2001). The MTL has been in use mostly in professional contexts (e.g. Amit \& Bar-Lev, 2013; Waldman, Galvin, \& Walumbwa, 2013) but has recently begun to see use in post-secondary institutions (Rosch et al., 2015). Cronbach's alpha results have historically been acceptable, ranging from .65 to .91. Within this study, they ranged from .74 (Social-normative) to .85 (Affectiveidentity). 
Leadership skill ("able"). We measured leadership skill with the Leader Behavior Scale (LBS), a 28-item instrument long in use and focused on assessing participant capacity to lead using transformational ("FORM") leadership behaviors and transactional ("ACT") leadership behaviors (Podsakoff, MacKenzie, Moorman, \& Fetter, 1990). The LBS has been a popular summary measure of leadership skill for over 20 years (Yukl, 2010), and has consistently demonstrated Cronbach alpha scores ranging from .71 to .89 (Yukl, 2010). Within this study, the alpha score for transformational leadership was .90 , while the same score for transactional leadership was .77.

Data Collection. All data was collected and organized during the 2014-2015 academic year. Each of the three institutions provided a simple random sample of 2,000 potential participants, who were contacted by email and invited to complete an online survey that contained the items listed above. Using Qualtrics online tools, each participant's survey items were randomized so that scales were not clustered, therefore introducing potentially unnecessary correlation across sub-scale items. Survey incentives, such as $\$ 50$ gift cards to Walmart, were employed as a result of a generous grant from the C. Charles Jackson Foundation. Potential participants who were non-responsive after the initial invite were re-invited to complete the survey through receipt of up to two reminder email contacts.

Data Analysis. To determine the degree to which students who report significant prior leadership training report elevated levels of leadership capacity, we calculated means and dispersion statistics for all scales and sub-scales for both the criterion and comparison groups. We then calculated unpaired independent samples t-tests for each of the six sub-scales (leader self-efficacy, each of the three motivation to lead sub-scales, and the two leadership skill subscales) to determine if differences between the two groups existed $(\mathrm{p}<.05)$ within each leadership capacity attribute.

To determine the degree to which students' cognitive models of effective leadership differed between the two groups, we conducted two series of confirmatory factor analyses (CFA) using maximum likelihood estimation, one series for each group. First, we examined the degree to which the two groups differed in their cognitive models of effective leadership capacity using the full six-factor "Ready, Willing and Able" leadership model (i.e. containing the two scales of leadership skill, the three scales of motivation to lead, and the single scale of leader efficacy). Within each sub-sample, we conducted a six-factor CFA and examined their fit statistics. To determine if a three-factor model might be more accurate for students participating in leadership programs (i.e. where the three motivation to lead and two leadership skill subscales were collapsed into single "motivation to lead" and "leadership skill" factors), we conducted a threefactor CFA within each group and compared the resulting fit statistics not only between groups, but to the six-factor results as well. Lastly, we conducted a single-factor CFA within each group that collapsed all scales into a single omnibus latent factor, and compared the resulting fit statistics between groups and across analyses. These series of analyses allowed for determining the most appropriate structure for the cognitive models of students with significant prior formal leadership program experience and their comparison sub-sample.

Methodological Limitations. While significant effort was made to ensure the rigor of the study, several methodological limitations must be mentioned prior to discussing results. 
While the study included three postsecondary institutions that were very different from each other, they as a whole are not representative of the breadth and diversity of post-secondary institutions. Results should be interpreted with this caution in mind. In addition, researchers left it up to participants to define what "counted" as a leadership development experience and what did not count. While this freedom allowed for participant agency and did not place the researcher as the arbiter of what experiences could and could not serve as supports to student leadership development, it also created potential ambiguity about the exact nature of the programs being evaluated. Lastly, while the proportion of underrepresented students from the perspective of racial identity within the sample was generally equal to their proportion at the universities included within the study, this did not change the fact that African-American and Latinx students represented only five percent of the overall study sample.

\section{Results}

We first calculated the mean and standard deviations of each sub-scale within the two groups and calculated an independent samples t-test for each sub-scale. These results are displayed in Table 1. Within each subscale, participants with repeated prior experience in formal leadership programs reported levels of leader self-efficacy, each type of motivation to lead, and both types of leadership skill that were not statistically different from the matched comparison group that possessed no formal experience.

Table 1. Scale means and t-test results.

\begin{tabular}{lcccc} 
& Significant Experience $\mu(\mathrm{SD})$ & No Experience $\mu(\mathrm{SD})$ & $t$ & $p$ \\
\hline Self-Eff for Leadership & $4.01(0.53)$ & $3.95(0.51)$ & 1.30 & .20 \\
MotToLead_AffId & $3.60(0.63)$ & $3.48(0.68)$ & 1.89 & .06 \\
MotToLead_NonCalc & $3.72(0.60)$ & $3.67(0.63)$ & 0.95 & .34 \\
MotToLead_SocNor & $3.71(0.48)$ & $3.71(0.47)$ & -0.09 & .93 \\
Transformational Skill & $3.98(.043)$ & $3.96(0.40)$ & 0.53 & .60 \\
Transactional Skill & $4.19(0.53)$ & $4.19(0.50)$ & -0.10 & .92 \\
\hline
\end{tabular}

We then sought to examine participants' cognitive models of effective leadership capacity by comparing the results of two six-factor CFA analyses where each survey subscale within the "Ready, Willing, and Able" model comprised a factor. The model resulting from the analysis of the sample of students with no prior leadership experience did not achieve a statistically appropriate representation of the expected shape of the data $\left(\chi^{2}{ }_{1875}=3778.40\right.$, $\mathrm{CMIN} / \mathrm{DF}=2.02$, $\mathrm{CFI}=0.59$, RMSEA $=.08$, PCFI $=0.56$ ), all of which fall well below recommended levels (Hu \& Bentler, 1999). CFI (“Comparative Fit Index”), specifically, serves as a good overview statistic, and should be above 0.90 to consider data to be "a good fit" (Hu \& Bentler). In addition, PCFI ("Parsimony Comparative Fit Index") serves as a measure of the economy of a survey scale; a PCFI statistic above 0.90 , for example, indicates that a scale is approximately the appropriate length for measuring a latent construct. Here, a finding of 0.64 indicates several survey items overlapped in the degree to which they contribute to larger meaning, indicating that participants were not able to distinguish fine meaning between leadership concepts. 
An identical CFA analysis conducted on data collected from participants who reported significant prior experience in formal leadership training yielded relatively similar results, however. The model produced an arguably slightly better goodness of fit, yet was not nearly differentiated enough to be considered a statistically appropriate representation of the expected shape of the data $\left(\chi^{2}{ }_{1875}=5376.32, \mathrm{CMIN} / \mathrm{DF}=2.87, \mathrm{CFI}=.69, \mathrm{RMSEA}=.07, \mathrm{PCFI}=.66\right)$. As within the comparison group, PCFI was low, suggesting that participants were unable to identify intra-individual differences across their degrees of leader self-efficacy, motivation to lead, and leadership skill.

A comparison of the two populations employing a three-factor model, where each of the five subscales were collapsed to single leader self-efficacy, motivation to lead, and leadership skill latent constructs, yielded similar results. The model produced from the participants with no leadership experience revealed a slightly worse fit compared to its respective six-factor model $\left(\chi^{2}{ }_{1887}=4353.65, \mathrm{CMIN} / \mathrm{DF}=2.30, \mathrm{CFI}=0.46, \mathrm{RMSEA}=.09, \mathrm{PCFI}=0.44\right)$. The results that emerged from participants with significant experience were also slightly worse than within its respective six-factor analysis $\left(\chi^{2}{ }_{1887}=6779.63, \mathrm{CMIN} / \mathrm{DF}=3.59, \mathrm{CFI}=0.57, \mathrm{RMSEA}=.08\right.$, $\mathrm{PCFI}=0.55)$.

A final comparison of the two populations resulted from employing a one-factor model, where each item was placed in a single omnibus latent factor of overall leadership capacity. The model that emerged from participants with no experience resulted in a slightly worse fit compared to both prior models $\left(\chi^{2}{ }_{1890}=4670.09, \mathrm{CMIN} / \mathrm{DF}=2.47, \mathrm{CFI}=0.39, \mathrm{RMSEA}=.10\right.$, $\mathrm{PCFI}=0.38$ ), with similar results emerging within the model for participants with significant prior experience $\left(\chi_{1890}^{2}=7425.24, \mathrm{CMIN} / \mathrm{DF}=3.93, \mathrm{CFI}=0.51, \mathrm{RMSEA}=.08, \mathrm{PCFI}=0.49\right)$.

\section{Discussion}

This study was designed to examine the degree to which students who repeatedly participate in formal programs of leadership development in postsecondary education report elevated levels of leader self-efficacy, motivation to lead, and leadership skill, and if those students display a more coherent cognitive model related to the capacity to lead within the "Ready, Willing, and Able" leadership model. The results of a series of independent samples ttests comparing scores between two groups matched on other relevant variables show that students who participate in formal programs report scores no different from their comparison peers on measures in all three areas. These findings differ from most prior research (e.g. Cress et al., 2001; Dugan \& Komives, 2010) that reveal significant differences between such groups, but by using less rigorous matching methods.

We included the additional step of conducting confirmatory factor analyses of scores across all three areas of leader self-efficacy, motivation to lead, and leadership skill to examine students' cognitive representation of these separate leadership capacity constructs. Our results suggested that students who participated in formal leadership development programs possessed a cognitive model of leadership potential that was little different than students with no formal prior experience in leadership development. The CFA results suggest that neither group of students were able to distinguish between transformational and transactional leadership behaviors, nor were they able to distinguish more broadly between leader self-efficacy, motivation to lead, and 
leadership skill. These results potentially indicate that leadership programs may not leave students more prepared to lead, and highlight the need to more deeply examine the cognitive structures of students as they undergo leadership development (Derue \& Ashford, 2010; Rosch \& Caza, 2012). If students who participate in programs possess similar scores and a cognitive model of their leadership capacity no more advanced than those with no experience, it is possible their participation may not have had much effect on student behaviors after participating. However, the parsimony-related statistical results suggested that the six-factor model of leadership capacity, that includes three sub-scales for motivation to lead and two sub-scales for leadership skill, represented a more rigorous and accurate way to measure student leadership capacity than simpler models.

Implications. These results present troubling data for leadership educators. When matched with a comparison group with similar background, students who repeatedly participate in leadership programs report levels of leadership capacity indistinguishable to students with no experience. Moreover, "fit" statistics resulting from the CFA showed both groups of student unprepared to lead. To be sure, leader self-efficacy, motivation to lead, and leadership skill scores of students should presumably all be inter-correlated. However, students who have taken the time and effort to participate in formal programs designed to help them build the capacity to engage in leadership behaviors should be able to distinguish between these three separate concepts. The results of this study imply that, even for students who have significant experience in the formal leadership development programs, leader self-efficacy, motivation to lead, and leadership skill were not represented as well-defined concepts within their cognitive models related to leadership capacity as a whole. Said another way, these results suggest that students either think of themselves as leaders, are motivated to lead, feel they will be successful if called upon, possess the skill to accomplish tasks in groups, and motivate their peers for success, or they lack all of these capacities - whether they have participated in formal co-curricular leadership training programs or they have not.

For educators. While the results of this study are concerning, they also indicate some potential for improving programs. Many leadership educators struggle with creating a balance between teaching "leadership studies" (e.g. ensuring students understand the three levels of the Social Change Model of Leadership Development) and teaching "leadership development" (e.g. helping students recognize how to productively apply concepts to own actions). Spending time focused on helping students learn the concepts of a leadership theory in a weekend retreat or a series of workshops may not ensure that students develop the capacity to lead. Moreover, many leadership programs focus on building leadership skill within their curriculum, to the detriment of a focus on building self-efficacy (Dugan, 2011) and motivation to lead (Rosch \& Villanueva, 2016). Research on the development of expertise (Zimmerman, 2006) reveals that people develop by learning to self-regulate their "covert" cognitive processes; in part, recognizing what they do not know or understand and practicing new behaviors until they become natural. Through a process of forethought, action, and post-action critical reflection, they can learn to regulate one's behavior to the point where effective behaviors are enacted without intentional thought. Recent research on pedagogical practices in leadership education programs show that, by far, the most common teaching tool educators bring to their programs is the use of group discussion (Jenkins, 2012). This 
practice, while helpful in eliciting common understanding of concepts, is not particularly well-suited to helping individuals develop personal expertise given their unique current capacity. As a whole, leadership educators could make their programs more effective by focusing their curriculum on the behaviors involved in effectively leading peers and organizational teams, while helping students become more mindful of the interrelated aspects of self-efficacy, motivation, and skill development to the effective practice of leadership. For example, leadership development courses should focus part of their curricula on developing motivation to lead within emerging leaders, for example, in addition to trainings that focus on skill-building for executive-level leaders.

For researchers. This study was conducted examining the leadership capacity and cognitive models of leadership involving a randomized sample of students at three diverse postsecondary institutions in the United States. More work is needed in two particular areas from researchers to help more fully inform our knowledge of the issues raised within this particular study. First, the population of students who participate in research focused on the impact of leadership training in higher education must be expanded to become even more representative of the broad population of students. Can these results be corroborated across expanded and diverse populations? Second, while the "Ready, Willing, and Able" impact model of leadership education represents a worthy outcome for developmental programs, few institutions explicitly focus on the model as a stated outcome within their programs. Do programs that focus explicitly on, for example, the Social Change Model of Leadership Development (Komives \& Wagner, 2017), show similar results using a CFA conducted using an instrument designed to measure capacity within the model, such as the Socially Responsible Leadership Scale (Slack, 2006)? The results of these future studies would serve to better inform leadership educators of the comprehensive impact of their programs.

\section{Conclusions}

This study was designed to examine the effects of participating in leadership programs on students beyond using methods designed to simply compare scores of students who participate to those who do not using pre-existing scales of leadership capacity. To do so, we used propensity scoring to build matched samples and confirmatory factor analysis across previously validated survey instruments designed to assess leader self-efficacy, motivation to lead, and leadership skill. Our goal using this method was to examine students' cognitive models of their capacity to engage in leadership behaviors. Our results suggested that students who participate in formal programs report levels of leadership capacity across all three areas no different to students who do not participate. Moreover, students who participate demonstrated no more coherent cognitive models of the three separate leadership concepts than students who have no experience in formal leadership development programs. These findings may indicate the lack of impact formal leadership programs has on the students who participate within them. 


\section{References}

Anmer, C. (1997). The American dictionary of idioms. Boston, MA: Houghton Mifflin.

Ammer, C. (2001). Clichés: Meanings and origins of more than 3,000 terms and expressions. New York, NY: Facts on File.

Amit, K., \& Bar-Lev, S. (2013). Motivation to lead in multicultural organizations: The role of work scripts and political perceptions. Journal of Leadership \& Organizational Studies, 20(2), 169-184. DOI: doi.org/10.1177/1548051812467206.

Avolio, B. J., Reichard, R. J., Hannah, S. T., Walumbwa, F. O., \& Chan, A. (2009). A metaanalytic review of leadership impact research: Experimental and quasi-experimental studies. The Leadership Quarterly, 20(5), 764-784. DOI: doi.org/10.1016/j.leaqua.2009.06.006.

Baddeley, A. (1979). The limitations of human memory: implications for the design of retrospective surveys. In Moss, L. and Goldstein, H. (Eds.), The recall method in social surveys, Volume 9, Studies in Education. (pp. 13-27). London: University Institute of Education.

Bandura, A. (1977). Self-efficacy: toward a unifying theory of behavioral change. Psychological review, 84(2), 191.

Banerji, S. (2007). Report: employers say college graduates lack essential skills to succeed in today's global economy. Diverse Issues in Higher Education, 23(26), 18.

Bass, B. M. (1998). Transformational Leadership. Hillsdale, NJ: Erlbaum.

Blunch, N.J. (2013). Introduction to structural equation modeling using IBM SPSS and AMOS. Thousand Oaks, CA: SAGE.

Chan, K.-Y., \& Drasgow, F. (2001). Toward a theory of individual differences and leadership: Understanding the motivation to lead. Journal of Applied Psychology, 86, 481-498.

Covey, S. R. (2004). The 7 habits of highly effective people. New York, NY: Simon \& Schuster Press.

Cress, C. M., Astin, H., Zimmerman-Oster, K., \& Burkhardt, J. C. (2001). Developmental outcomes of college students' involvement in leadership activities. Journal of College Student Development, 42, 15-27.

Day, D. V., \& Sin, H.-P. (2011). Longitudinal tests of an integrative model of leader development: Charting and understanding developmental trajectories. The Leadership Quarterly, 22(3), 545-560. DOI: doi.org/10.1016/j.leaqua.2011.04.011. 
Derue, D., \& Ashford, S. (2010). Who will lead and who will follow? A social process of leadership identity construction in organizations. Academy of Management Review, 35(4), 627-647. DOI: doi.org/10.5465/AMR.2010.53503267

Dinh, J. E., Lord, R. G., Gardner, W. L., Meuser, J. D., Liden, R. C., \& Hu, J. (2014). Leadership theory and research in the new millennium: Current theoretical trends and changing perspectives. The Leadership Quarterly, 25(1), 36-62. DOI: dx.doi.org/10.1016/j.leaqua.2013.11.005.

Dugan, J. P. (2011). Pervasive myths in leadership development: Unpacking constraints on leadership learning. Journal of Leadership Studies, 5(2), 79-84. DOI: doi.org/10.1002/jls.20223.

Dugan, J. P., Bohle, C. W., Gebhardt, M., Hofert, M., Wilk, E., \& Cooney, M. a. (2011). Influences of leadership program participation on students' capacities for socially responsible leadership. Journal of Student Affairs Research and Practice, 48(1), 65-84. DOI: doi.org/10.2202/1949-6605.6206.

Dugan, J. P., Garland, J. L., Jacoby, B., \& Gasiorski, A. (2008). Understanding commuter student self-efficacy for leadership: A within-group analysis. NASPA Journal, 45, 282310 .

Dugan, J. P., \& Komives, S. R. (2007). Developing leadership capacity in college students: Findings from a national study. A report from the Multi-Institutional Study of Leadership. College Park, MD: National Clearinghouse for Leadership Programs.

Dugan, J. P., \& Komives, S. R. (2010). Influences on college students' capacities for socially responsible leadership. Journal of College Student Development, 51, 525-549.

Hannah, S. T., Avolio, B. J., Luthans, F., \& Harms, P. D. (2008). Leadership efficacy: Review and future directions. The Leadership Quarterly, 19, 669-692.

Howard, G. S., Ralph, K. M., Gulanick, N. A., Maxwell, S. E., Nance, D. W., \& Gerber, S. K. (1979). Internal invalidity in pretest-posttest self-report evaluations and a re-evaluation of retrospective pretests. Applied Psychological Measurement, 3(1), 1-23.

Hoyt, C. L. (2005). The role of leadership efficacy and stereotype activation in women's identification with leadership. Journal of Leadership and Organizational Studies, 11(4), $2-14$.

Hu, L. T., \& Bentler, P. M. (1999). Cutoff criteria for fit indexes in covariance structure analysis: Conventional criteria versus new alternatives. Structural Equation Modeling: A Multidisciplinary Journal, 6(1), 1-55.

International Leadership Association. (2017). Leadership Program Directory. Retrieved from: http://www.ila-net.org/Resources/LPD/index.htm 
Jenkins, D. (2012). Exploring signature pedagogies in undergraduate leadership education. Journal of Leadership Education, 11(1), 1-27.

Keating, K., Rosch, D. M., \& Burgoon, L. (2014). Developmental readiness for leadership: The differential effects of leadership courses on creating "ready, willing, and able" leaders. Journal of Leadership Education, 13(3), 1-16. DOI: doi.org/1012806/V13/I3/R1

Kezar, A. J., \& Moriarty, D. (2000). Expanding our understanding of student leadership development: A study exploring gender and ethnic identity. Journal of College Student Development, 41(1), 55-69.

Kline, R.B. (2011). Principles and practices of structural equation modeling. New York, NY: Guilford Press.

Komives, S. R., \& Wagner, W. (Eds.). (2017). Leadership for a better world: Understanding the Social Change Model of Leadership Development. (2nd ed.). San Francisco, CA: JosseyBass.

Machida, M., \& Schaubroeck, J. (2011). The Role of Self-Efficacy Beliefs in Leader Development. Journal of Leadership \& Organizational Studies, 18, 459-468. DOI: doi.org/10.1177/1548051811404419.

McCormick, M. J. (2001). Self-efficacy and leadership effectiveness: Applying social cognitive theory to leadership. Journal of Leadership \& Organizational Studies, 8(1), 22-33.

Multi-Institutional Study of Leadership. www.leadershipstudy.net.

Murphy, S. E. (2002). Leader self-regulation: The role of self-efficacy and multiple intelligences. Multiple intelligences and leadership. In R. E. Riggio, S. E. Murphy, \& F. J. Pirozzolo (Eds.), Multiple intelligences and leadership, LEA's organization and management series (pp. 163-186). Mahwah, NJ: Erlbaum.

Murphy, S. E., \& Ensher, E. A. (1999). The effects of leader and subordinate characteristics in the development of leader-member exchange quality. Journal of Applied Social Psychology, 29, 1371-1394. DOI: doi.org/10.1111/j.1559-1816.1999.tb00144.x.

Murphy, S. E., \& Fiedler, F. E. (1992). The contribution of leadership experience and selfefficacy to group performance under evaluation apprehension. (Unpublished doctoral dissertation). University of Washington, Seattle, WA.

Murphy, S. E., \& Johnson, S. K. (2011). The benefits of a long-lens approach to leader development: Understanding the seeds of leadership. Leadership Quarterly, 22(3), 459470. DOI: doi.org/10.1016/j.leaqua.2011.04.004. 
National Association of Colleges and Employers. (2015). Job outlook 2013. Bethlehem, PA: National Association of Colleges and Employers.

Northouse, P. G. (2010). Leadership: Theory and practice, 5th Edition. Thousand Oaks, CA: Sage Press.

Nulty, D. D. (2008). The adequacy of response rates to online and paper surveys: what can be done?. Assessment \& evaluation in higher education, 33, 301-314.

Owen, J. (2012). Examining the design and delivery of collegiate student leadership development programs: Findings from the Multi-Institutional Study of Leadership (MSL$I S)$, a national report. Washington, DC: Council for the Advancement of Standards in Higher Education.

Parker, E. T., \& Pascarella, E. T. (2013). Effects of diversity experiences on socially responsible leadership over four years of college. Journal of Diversity in Higher Education, 6(4), 219-230. DOI: doi.org/10.1037/a0035130.

Pearson, R.W. (2010). Statistical persuasion: How to collect, analyze and present data... accurately, honestly, and persuasively. Thousand Oaks, CA: SAGE.

Podsakoff, P. M., MacKenzie, S. B., Moorman, R. H., \& Fetter, R. (1990). Transformational leader behaviors and their effects on followers' trust in leader, satisfaction, and organizational citizenship behaviors. The Leadership Quarterly, 1, 107-142. DOI: doi.org/10.1016/1048-9843(90)90009-7

Rosch, D. M., \& Villanueva, J. C. (2016). Motivation to develop as a leader. New directions for student leadership, 149, 49-59. DOI: 10.1002/yd.20161.

Rosch, D. M., \& Caza, A. (2012). The durable effects of short-term programs on student leadership development. Journal of Leadership Education, 11(1), 28-48.

Rosch, D. M., Collier, D., \& Thompson, S. E. (2015). An exploration of students' motivation to lead: An analysis by race, gender, and student leadership behaviors. Journal of College Student Development, 56, 286-291.

Rosch, D. M., \& Schwartz, L. M. (2009). Potential Issues and Pitfalls in Outcomes Assessment in Leadership Education. Journal of Leadership Education, 8(1), 177-194.

Rosenthal, S. A. (2012). National leadership index 2012: A national study of confidence in leadership. Cambridge, MA: Center for Public Leadership, Harvard Kennedy School.

Slack, C. (2006). Socially responsible leadership scale revised version 2: Using the SRLS-R2 for research and assessment. College Park, MD: National Clearinghouse for Leadership Programs. 
Waldman, D. A., Galvin, B. M., \& Walumbwa, F. O. (2013). The development of motivation to lead and leader role identity. Journal of Leadership \& Organizational Studies, 20(2), 156-168. https://doi.org/10.1177/1548051812457416

Yukl, G. (2010). Leadership in organizations (7th ed.). Upper Saddle River, NJ: Prentice Hall.

Zimmerman, B. J. (2006). Development and adaptation of expertise: The role of self-regulatory processes and beliefs. In K. A. Ericsson, N. Charness, P. J. Feltovich, \& R. R. Hoffman (Eds.), The Cambridge handbook of expertise and expert performance (pp. 705-722). New York, NY, US: Cambridge University Press. 